\title{
Downhill Speed Control of In-Wheel Motor During Regenerative Braking
}

\author{
Raif Bayır ${ }^{1}$, Tuncay Soylu ${ }^{2}$ \\ ${ }^{I}$ Technology Faculty, Department of Mechatronics Engineering, Karabuk University, \\ Karabuk, 78050, Turkey \\ ${ }^{2}$ Institue of Natural and Applied Sciences, Department of Electric and Electronics Engineering, \\ Karabuk University, \\ Karabuk, 78050, Turkey \\ rbayir@karabuk.edu.tr
}

\begin{abstract}
Recovering kinetic energy in an electric vehicle is important in order to use battery more effective and to extend the vehicle's maximum distance range. In this study, regenerative braking is simulated and implemented on a test bed for a lightweight electric vehicle on the three different downhill that are $3^{\circ}, 4^{\circ}$ and $5^{\circ}$ slopes at $30 \mathrm{~km} / \mathrm{h}$ conditions. An in-wheel motor which is generally used in the light electric vehicle is used for the regenerative braking application. Speed of the in-wheel motor is controlled with PID controller during regenerative braking. The in-wheel motor charges batteries and the PID controller maintain speed of the in-wheel motor to reference speed in both simulation study and experimental study. Graphics and outcomes of the simulation and experiment are showed in the results and discussion section.
\end{abstract}

Index Terms-In-wheel motor; regenerative braking; PID controller.

\section{INTRODUCTION}

Electric vehicle technologies are rapidly growing through the cheap and clean energy advantages; however, electric vehicles have a range problem. Implementation of regenerative braking is very important because of effective usage of storage energy in batteries. Vehicles massively consume energy during acceleration and uphill applications. The energy should be recovered during deceleration and downhill.

Regenerative braking cooperation with ABS (Anti-lock braking system) and only regenerative braking anti-lock are studied [1], [2]. Friction braking and automatic transmission cooperate with regenerative braking as aimed optimum energy recovery [3]-[7]. Regenerative braking is controlled by the fuzzy logic controller [8]-[10]. Regenerative braking control and management strategies are developed considering the temperature of batteries, motor and motor driver, charging current, battery voltage, deceleration, the pressure of braking pedal [11]-[16]. Downhill safety assistance is executed to help driver of the vehicle [17]. Electronic stability control and lateral stability control with regenerative braking are studied [18], [19].

Regenerative braking is crucial for electric vehicles to increase distance range of electric vehicles. However, there

Manuscript received 5 February, 2017; accepted 11 September, 2017.

This study was supported by Karabuk University within the scope of Scientific Research Projects with KBU-BAP-13/2-DR-007 code. are some difficulties to execution of regenerative braking on real vehicles. For this aim, regenerative braking with IWM (in-wheel motor) is executed in simulation study with using Matlab/Simulink and experimental study on a test bed for based a $300 \mathrm{~kg}$ lightweight electric vehicle on $3^{\circ}, 4^{\circ}$ and $5^{\circ}$ slopes downhill at $30 \mathrm{~km} / \mathrm{h}$ reference speed. PID controller is used to change duty of PWM (pulse with modulation) to maintain the speed of the IWM during regenerative braking [20], [21]. The speed is successfully controlled, the batteries of IWM are charged during the simulation and experiment. Subject of this study is different from literature mentioned above as cooperation braking, optimum or maximum energy recovery, stability control and management strategy of regenerative braking.

\section{MATHEMATICAL EQUATIONS OF AN IN-WHEEL MOTOR}

Mathematical equations of IWM are need to be known to simulate an IWM although Matlab/Simulink already has the model of an IWM as PMSM (permanent magnet synchronous machine) which is basically BLDC (brushless DC motor). Different results can be obtained by an IWM parameters or controller changing in simulation that saves time. A DC motor mathematical equation is required to be observed in order to understand an IWM mathematical equation.

A DC motor electrical presentation is shown in Fig. 1. When voltage apply to DC motor terminal, current flows DC motor windings and rotor of the motor starts to rotate and generates BEMF (back electromagnetic force). DC motor mathematical equation is (1).

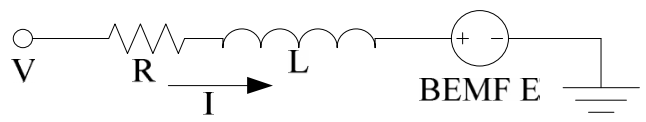

Fig. 1. DC motor electrical presentation.

$$
V=I \cdot R+L \cdot \frac{d I}{d t}+E,
$$

where $V$ is applied voltage to motor terminals, $I$ is current flows winding of the motor, $R$ is resistor of motor terminals, $L$ is inductance of motor terminals, $E$ is BEMF which produced by the motor.

An IWM electrical presentation is shown in Fig. 2. Phase 
inductances, resistances of in-wheel motor are assumed equal. Mathematical equation of the IWM is (2) in matrix form.

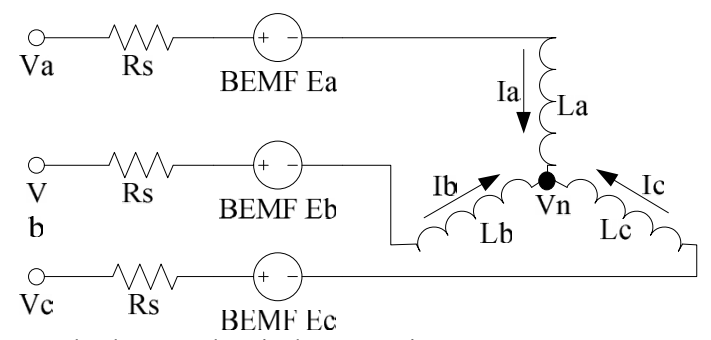

Fig. 2. In-wheel motor electrical presentation.

$$
\begin{gathered}
{\left[\begin{array}{c}
V_{a n} \\
V_{b n} \\
V_{c n}
\end{array}\right]=\left[\begin{array}{ccc}
R_{S} & 0 & 0 \\
0 & R_{S} & 0 \\
0 & 0 & R_{S}
\end{array}\right] \times\left[\begin{array}{c}
I_{a} \\
I_{b} \\
I_{c}
\end{array}\right]+} \\
+\frac{d}{d t} \times\left[\begin{array}{ccc}
L_{a a} & L_{a b} & L_{a c} \\
L_{b a} & L_{b b} & L_{b c} \\
L_{c a} & L_{c b} & L_{c c}
\end{array}\right] \times\left[\begin{array}{c}
I_{a} \\
I_{b} \\
I_{c}
\end{array}\right]+\left[\begin{array}{c}
E_{a} \\
E_{b} \\
E_{c}
\end{array}\right],
\end{gathered}
$$

where $V_{a n}, V_{b n}$ and $V_{c n}$ are difference between motor terminal and $V_{n}$ mid-point. $V_{n}, V_{a n}, V_{b n}$ and $V_{c n}$ are calculated as in (3)-(6). $R_{s}$ is phase resistance, $I_{a}, I_{b}$ and $I_{c}$ are phases currents, $L_{\mathrm{aa}}, L_{\mathrm{bb}}$ and $L_{\mathrm{cc}}$ are phase inductances, $L_{\mathrm{ab}}, L_{\mathrm{ac}}, L_{\mathrm{ba}}$, $L_{\mathrm{bc}}, L_{\mathrm{ca}}$ and $L_{\mathrm{cb}}$ are mutual inductances, $E_{\mathrm{a}}, E_{\mathrm{b}}$ and $E_{\mathrm{c}}$ are BEMF:

$$
\begin{gathered}
V_{n}=\left(V_{a}+V_{b}+V_{c}-E_{a}-E_{b}-E_{c}\right) / 3, \\
V_{a n}=V_{a}-V_{n}, \\
V_{a n}=V_{b}-V_{n}, \\
V_{c n}=V_{c}-V_{n} .
\end{gathered}
$$

Equation (7) gives phases inductances. Equation (8) gives mutual inductance as M. Mutual inductance can be described as when current flows in a winding that winded on core, other winding on the same core are affected:

$$
\begin{gathered}
L=L_{a a}=L_{b b}=L_{c c} \\
M=L_{a b}=L_{a c}=L_{b a}=L_{b c}=L_{c a}=L_{c b} .
\end{gathered}
$$

Equation (9) is obtained, if (7) and (8) are written in (2)

$$
\begin{aligned}
& {\left[\begin{array}{l}
V_{a n} \\
V_{b n} \\
V_{c n}
\end{array}\right]=\left[\begin{array}{ccc}
R_{S} & 0 & 0 \\
0 & R_{S} & 0 \\
0 & 0 & R_{S}
\end{array}\right] \times\left[\begin{array}{c}
I_{a} \\
I_{b} \\
I_{c}
\end{array}\right]+} \\
& +\frac{d}{d t} \times\left[\begin{array}{ccc}
L & M & M \\
M & L & M \\
M & M & L
\end{array}\right] \times\left[\begin{array}{c}
I_{a} \\
I_{b} \\
I_{c}
\end{array}\right]+\left[\begin{array}{c}
E_{a} \\
E_{b} \\
E_{c}
\end{array}\right] .
\end{aligned}
$$

Sum of current incoming to node is zero as in (10). Mathematical equations are given in (10) and (11). Equation (12) is obtained, if (11) is written to (9):

$$
\begin{gathered}
0=I_{a}+I_{b}+I_{c}, \\
M \cdot I_{a}=-M \cdot I_{b}-M \cdot I_{c},
\end{gathered}
$$

$$
\begin{gathered}
{\left[\begin{array}{c}
V_{a n} \\
V_{b n} \\
V_{c n}
\end{array}\right]=\left[\begin{array}{ccc}
R_{S} & 0 & 0 \\
0 & R_{S} & 0 \\
0 & 0 & R_{S}
\end{array}\right] \times\left[\begin{array}{c}
I_{a} \\
I_{b} \\
I_{c}
\end{array}\right]+} \\
+\frac{d}{d t} \times\left[\begin{array}{ccc}
L-M & 0 & 0 \\
0 & L-M & 0 \\
0 & 0 & L-M
\end{array}\right] \times\left[\begin{array}{c}
I_{a} \\
I_{b} \\
I_{c}
\end{array}\right]+\left[\begin{array}{c}
E_{a} \\
E_{b} \\
E_{c}
\end{array}\right] .
\end{gathered}
$$

\section{REGENERATIVE BRAKING OF THE IN-WHEEL MOTOR}

The IWM in the study is a kind of a BLDC motor. The difference is IWMs have more pole pairs, more torque, less revolution speed. A driver is needed for IWM to make rotation or regenerative braking. The in-wheel motor has 3 Hall Effect sensors which detect the position of the IWM. The IWM driver is consist of 3 half bridge Mosfets. According to the position of the in-wheel motor Mosfets are triggered. There is an example for regenerative braking of the IWM for one phase. The IWM is considered to turn enough speed to implement regenerative braking. When PWM signal is digital ' 1 ', $\operatorname{Tr} 2$ Mosfet and $\operatorname{Tr} 4$ diode become conductive and inductor of the IWM is charged by the current flow as in Fig. 3. When PWM signal is digital ' 0 ' and charged inductor voltage is higher than the battery voltages, the current flows through $\operatorname{Tr} 4$ and $\operatorname{Tr} 1$ diodes as in Fig. 4. The main idea of regenerative braking is the same as boost converter but has some rules. Battery SOC (state of charge) should be less than $70 \%$. The IWM should rotate at least $100 \mathrm{rpm}$ because of PWM duty restriction. PWM duty should be between $40 \%-80 \%$. Despite lack of regenerative efficiency, less than duty of $40 \%$ would generate enough energy to charge the battery but less effect on braking. Higher than duty of $80 \%$ has effect on braking but efficiency of regenerative braking drops significantly and driver of the IWM could be damaged due to serious amount of current flowing.

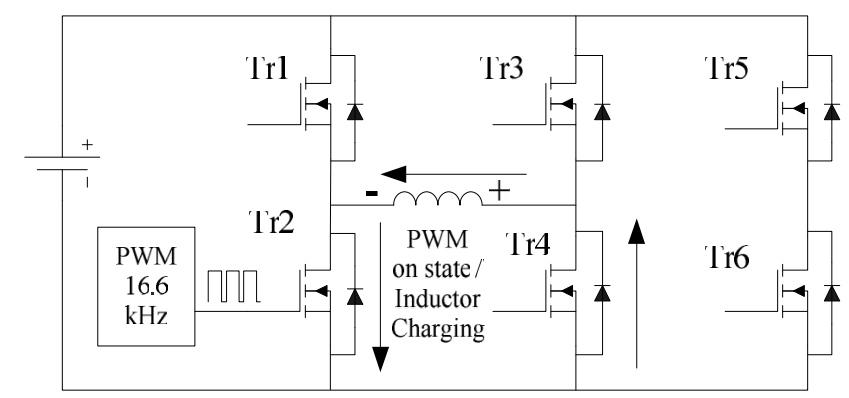

Fig. 3. Current flows when PWM signal is digital ' 1 '.

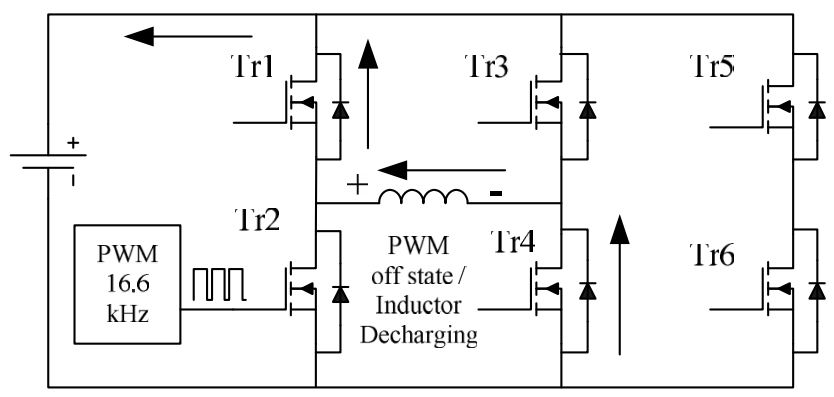

Fig. 4. Current flows when PWM signal is digital ' 0 '. 


\section{MATERIALS AND METHOD}

The IWM should be rotated for implementation of regenerative braking. For this reason, the IWM is coupled with a DC motor on a test bed. The DC motor has $7.5 \mathrm{~kW}$ power and generates $45 \mathrm{Nm}$ torque and the IWM has $3 \mathrm{~kW}$ power and generates $45 \mathrm{Nm}$. The IWM is synchronous permanent magnet and has outside rotor. 28 pole pair is existed in the stator. The test bed appearance is showed in Fig. 5. The DC motor is torque controlled by a FLC (fuzzy logic controller) as the reference and feedback inputs are current. The current sensor is LEM LTS25P which can measure up to $80 \mathrm{~A}$. The feedback current subtracts from the reference and error is defined. The error and derivative of the error are inputs for the FLC. Inputs and output membership of the FLC are showed in Fig. 6 and the rule base of the FLC is presented in Table I. The FLC is created from Matlab Fuzzy Logic Toolbox. The FLC is executed by STM32F4 Discovery card [22]. STM32F4 is programmed as embed system from Matlab/Simulink.

The IWM is controlled by a IWM driver as $16.6 \mathrm{kHz}$ PWM frequency. IR2104 is used for Mosfet driver. 4 pcs serially connected $72 \mathrm{~A}, 12 \mathrm{~V}$ batteries are used to charge. Battery current, voltage, and revolution speed of the system is recorded to a PC by Advantech 1716 DAQ (data acquisition card) [23]. Experimental system blocks are shown in Fig. 7. LEM LA55P which measures up to $90 \mathrm{~A}$ is used for current monitoring; LEM LV25P which measures up to $500 \mathrm{~V}$ is used for voltage monitoring. System revolution speed is measured by an inductive sensor and a frequency voltage convertor. Matlab environment is used for record.

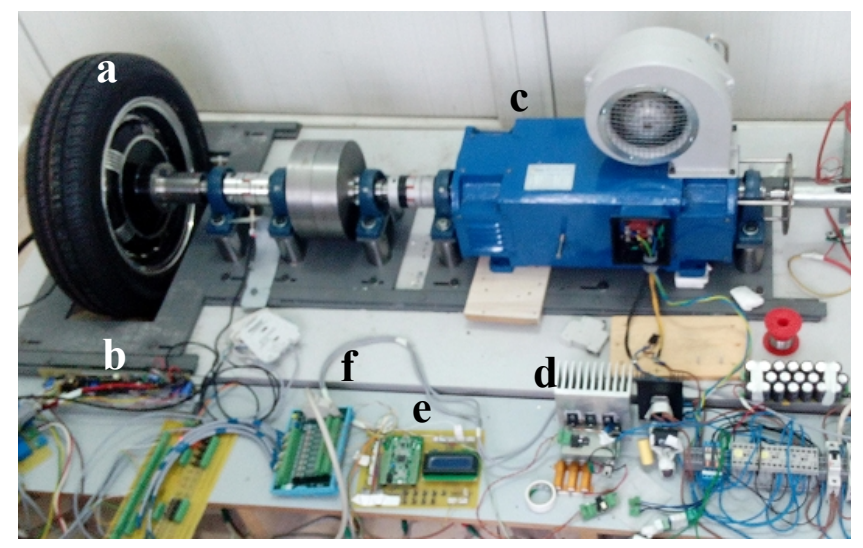

Fig. 5. Test bed of the IWM appearance: $\mathrm{a}$ - In wheel motor; $\mathrm{b}-$ In wheel motor driver; c - DC motor; d - DC motor driver; e - DC motor speed controller; f-DAQ Terminal board.

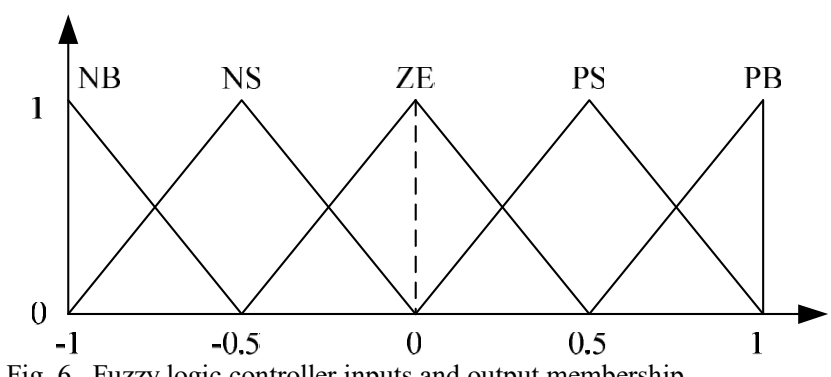

Fig. 6. Fuzzy logic controller inputs and output membership.

The IWM is controlled with a PID controller during regenerative braking thus reference and feedback are revolution speed. The PID controller of the IWM is shown in Fig. 8. Reference speed is subtracted to actual speed due to the regenerative braking application to calculate error as $\mathrm{e}(\mathrm{t}) \mathrm{Kp}, \mathrm{Ki}$ and $\mathrm{Kd}$ are coefficients that are determined by experiment in the study. PID controller equation is given in (13).

$$
u(t)=K p \cdot e(t)+K i \int e(t) \cdot d t+K d \cdot \frac{d e(t)}{d t}
$$

TABLE I. FUZZY LOGIC CONTROLLER RULE BASE.

\begin{tabular}{|c|c|c|c|c|c|}
\hline e/de & NB & NS & ZE & PS & PB \\
\hline NB & NB & NB & NS & NS & ZE \\
\hline NS & NB & NS & NS & ZE & PS \\
\hline ZE & NS & NS & ZE & PS & PS \\
\hline PS & NS & ZE & PS & PS & PB \\
\hline PB & ZE & PS & PS & PB & PB \\
\hline
\end{tabular}

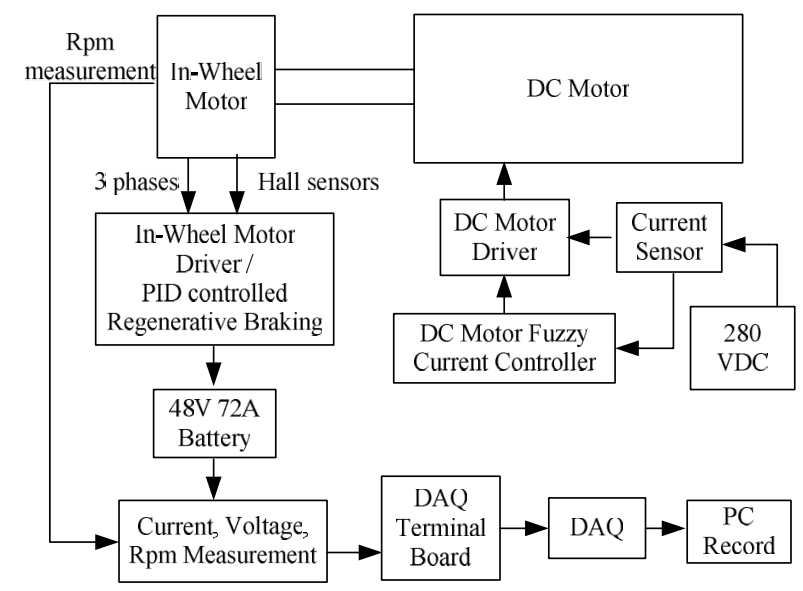

Fig. 7. Experimental system block diagram.

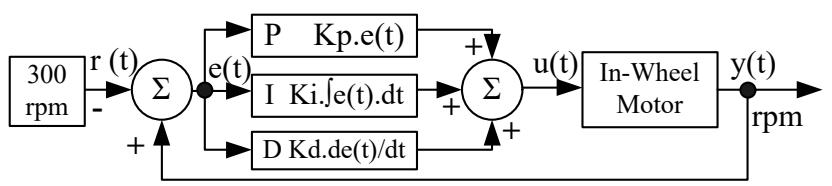

Fig. 8. PID controller block diagram of the IWM for regenerative braking.

Speed control of $300 \mathrm{~kg}$ weight an electric vehicle on $3^{\circ}$, $4^{\circ}$ and $5^{\circ}$ slopes downhill at $30 \mathrm{~km} / \mathrm{h}$ speed and has $53 \mathrm{~cm}$ diameter of wheel is calculated as (14), (15) and (16):

$$
\begin{gathered}
L=\sin (\alpha) \cdot m . G . r, \\
R=V .1000 /(60 . c), \\
P=R . L / 9.549,
\end{gathered}
$$

where $L, \alpha, m, G, r, R, V, c, P$ are respectively load as $\mathrm{Nm}$, slope as degree, vehicle weight as $\mathrm{kg}$, Earth gravity as $\mathrm{m} / \mathrm{s}^{2}$, radius of wheel as $\mathrm{m}$, revolution speed as rpm, velocity as $\mathrm{km} / \mathrm{h}$, circumference of wheel as $\mathrm{m}$, power as Watt. As result of the calculations, the loads for $3^{\circ}, 4^{\circ}$ and $5^{\circ}$ slopes are respectively $40.82 \mathrm{Nm}, 54.4 \mathrm{Nm}$ and $67.97 \mathrm{Nm}$, revolution speed is $300 \mathrm{rpm}$, output powers are respectively $1282 \mathrm{~W}$, $1709 \mathrm{~W}$ and $2135 \mathrm{~W}$. If the electric vehicle is considered four wheel drives, respectively $10.2 \mathrm{Nm}, 13.2 \mathrm{Nm}$ and $17 \mathrm{Nm}$ torques, and $321 \mathrm{~W}, 427 \mathrm{~W}$ and $534 \mathrm{~W}$ powers are calculated for one IWM. 


\section{Simulation Studies of Regenerative Braking}

Simulation of regenerative braking of the IWM is carried out on Matlab/Simulink as seen in Fig. 9. PMSM block of Simulink is used as the IWM. Due to the obtaining positive revolution speed, negative load is applied to the IWM as $-10.2 \mathrm{Nm},-13.6 \mathrm{Nm},--17 \mathrm{Nm}$. Phase selector is created for selecting proper phases of the IWM thanks to hall sensor outputs of the IWM. DC inverter block has 3 half bridge Mosfets. A 48 V, 75 Ah lead acid battery of Simulink is connected to the DC inverter block as $50 \%$ state of charge. A Simulink PID block is used to control regenerative braking of the IWM. PID controller and the IWM parameters are given in Table II. Actual revolution speed is subtracted the reference revolution speed of $300 \mathrm{rpm}$. PWM frequency is set to $1 \mathrm{kHz}$. Sampling time of the simulation is $0.000001 \mathrm{~s}$. PWM frequency should be $16.6 \mathrm{kHz}$ as set experimental study, however increasing PWM frequency decreases sampling time that causes memory problems and time loosing.

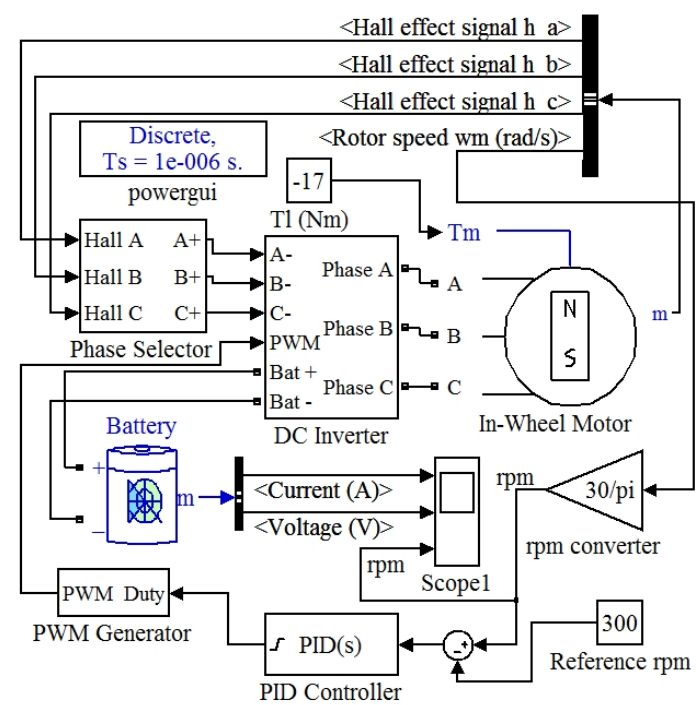

Fig. 9. Simulation of the IWM for regenerative braking.

TABLE II. PID CONTROLLER AND THE IWM PARAMETERS.

\begin{tabular}{|c|c|c|c|}
\hline PID Parameters & Values & IWM Parameters & Values \\
\hline Kp & 1 & Stator Phase Resistance & $0.0757 \Omega$ \\
\hline Ki & 1 & Stator Phase Inductance & $0.1 \mathrm{mH}$ \\
\hline Upd & 0.005 & Torque Constant & $0.57 \mathrm{~N} . \mathrm{m} / \mathrm{A}$ \\
\hline Lower sat. limit & 0 & Inertia & $0.1 \mathrm{~kg} . \mathrm{m}^{2}$ \\
\hline Anti-windup & Clamping & Priction Factor & $0.001 \mathrm{~N} . \mathrm{m} . \mathrm{s}$ \\
\hline
\end{tabular}

\section{EXPERIMENTAL STUDIES OF REGENERATIVE BRAKING}

An IWM driver that supports embed system is developed and created. Hall sensors, supply current, supply voltage and temperature of Mosfets of the IWM are inputs of the driver. 3 phases and LCD screen are output of the driver. A Matlab/Simulink model is embedded to the driver as seen in Fig. 10. STM32F4 Discovery card is used as a microcontroller. Sample time of the microcontroller is $0.0001 \mathrm{~s}$. Phase selection is executed with using interrupt of the microcontroller. Revolution speed is measured from one of the hall sensors. Reference speed is set to $300 \mathrm{rpm}$. PID controller of Matlab/Simulink is used and the parameter of
PID controller is the same as simulation study of regenerative braking.

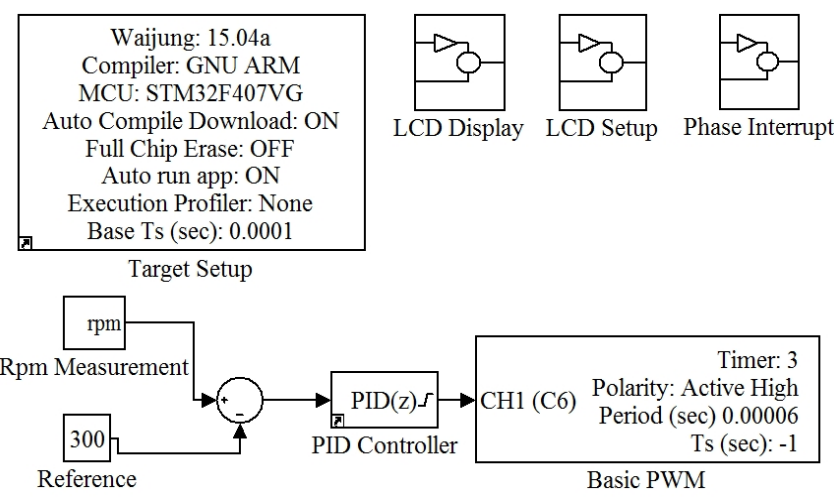

Fig. 10. Matlab/Simulink model for the driver of the IWM.

The torque controlled DC motor loads the IWM for regenerative braking as $1.8 \mathrm{~A}, 2.4 \mathrm{~A}$ and $3 \mathrm{~A}$ that are corresponded $3^{\circ}, 4^{\circ}$ and $5^{\circ}$ slope of downhill.

\section{RESULTS AND DISCUSSION}

Regenerative braking application is simulated in Matlab/Simulink. The revolution reference speed is set to $300 \mathrm{rpm}$, however phase revolution is $8400 \mathrm{rpm}$ which means 140 revolution per second due to the 28 pole pair of the IWM. The PWM frequency is needed to be set higher than revolution which is $1 \mathrm{kHz}$. PWM duty resolution is considered 0.001. Result of the situation, sampling time is set to $0.000001 \mathrm{~s}$. Although real experiment time is $180 \mathrm{~s}$, the simulation study is only $15 \mathrm{~s}$ because of memory problems. Each simulation experiment takes more than 40 minutes. Revolution speed of the IWM, battery current and battery voltage are results of the simulation and each result has $15 \mathrm{M}$ data.

The regenerative braking simulation is carried out based for light weight electric vehicle dynamic on different downhill slopes which are $3^{\circ}, 4^{\circ}$ and $5^{\circ}$ that are corresponded respectively $10.2 \mathrm{Nm}, 13.6 \mathrm{Nm}$ and $17 \mathrm{Nm}$. Revolution speed results of the simulation study are given Fig. 11. Rising time of rapid slope is less due to the high load torque. PID controller succesfully settles all load of downhill slopes.

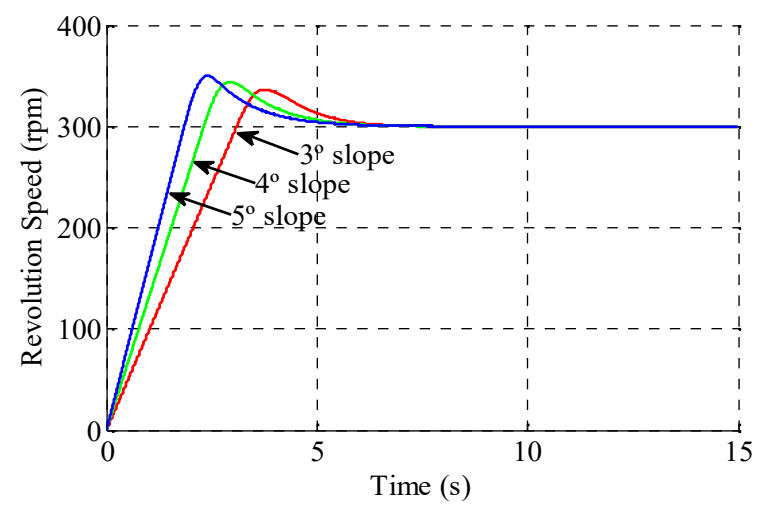

Fig. 11. Revolution speed of simulation study of regenerative braking

Battery current results of the simulation study are shown in Fig. 12. Low past filter is used to eliminate PWM frequency. The current graphics are negative that means 
battery is charged on each slope. Regenerative braking on rapid slope gives more current as expected.

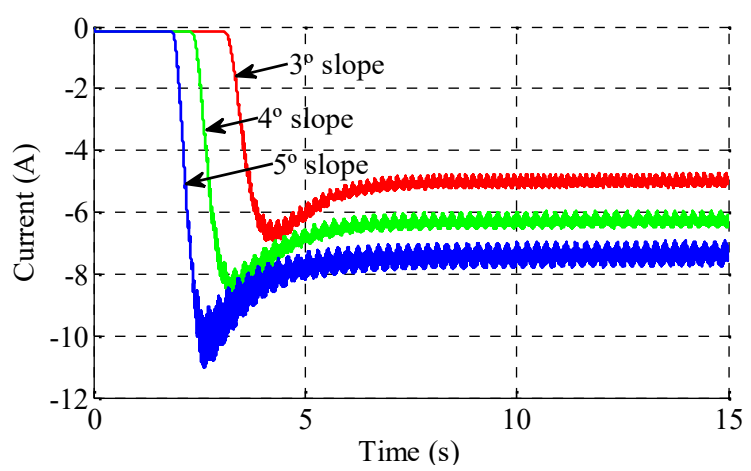

Fig. 12. Battery currents of simulation study of regenerative braking.

Battery voltage results of the simulation study are presented in Fig. 13. Low past filter is used to eliminate PWM frequency. The voltage results indicate that battery SOC increases on each slope. Rapid slop has greater rising as a result of higher current charging.

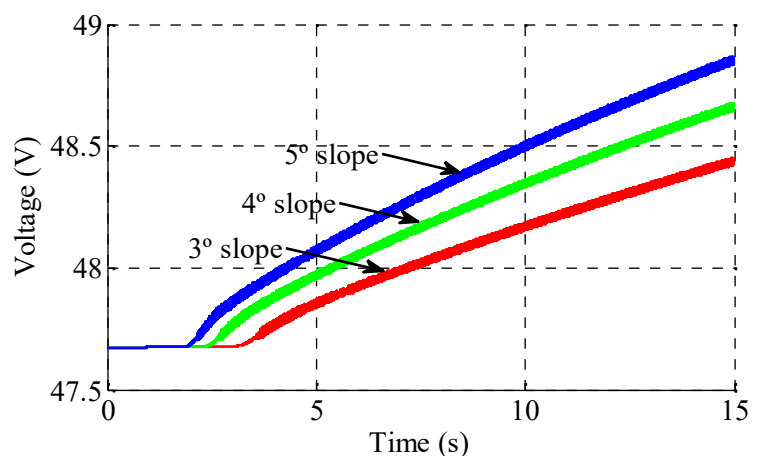

Fig. 13. Battery voltages of simulation study of regenerative braking.

The experimental regenerative braking of is studied on the test bed of the IWM. The torque controlled DC motor runs with $1.8 \mathrm{~A}, 2.4 \mathrm{~A}$ and $3 \mathrm{~A}$ input references that are corresponded respectively $3^{\circ}, 4^{\circ}$ and $5^{\circ}$ slope of downhill. The speed of the IWM is controlled at $300 \mathrm{rpm}$ with PID controller. The revolution speed graphs of the IWM of the regenerative braking experiment are given in Fig. 14. The IWM revolution speeds are settled to the reference of revolution speed with PID controller. As simulation results, rapid slope has less rising time due to the greater load.

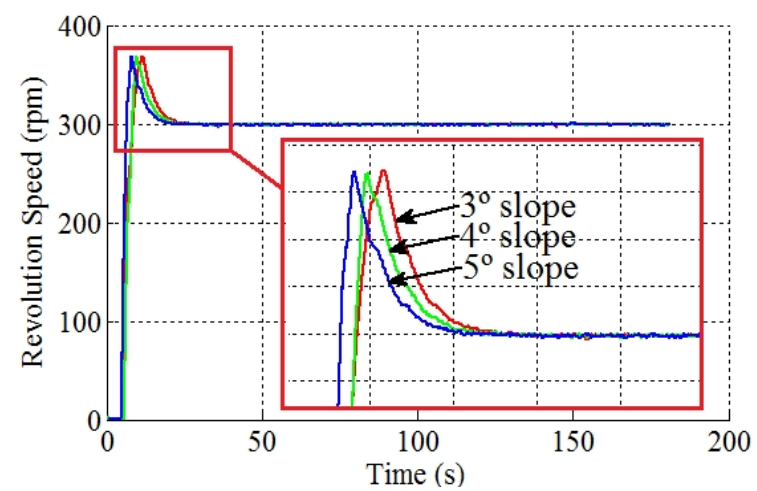

Fig. 14. Revolution speed of experimental study of regenerative braking.

The batteries current of the experimental study of regenerative braking is presented in Fig. 15. Low past filter is used for current graphs in order to filter PWM frequency.
There are similarities with simulation results as rapid slope has more charging current.

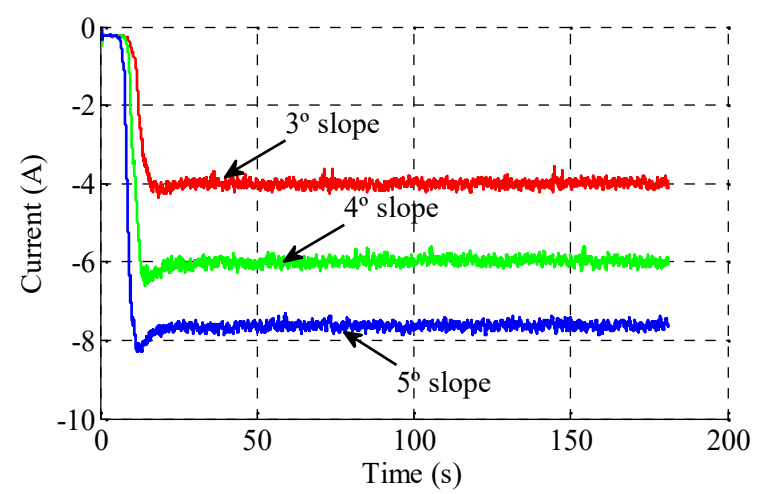

Fig. 15. Batteries currents of experimental study of regenerative braking.

Voltages of the batteries of the regenerative braking experiment study is shown in Fig. 16. Low past filter is used for voltage graphs in order to eliminate PWM frequency. Rapid slope voltage is greater because of the higher charging current as in the simulation study.

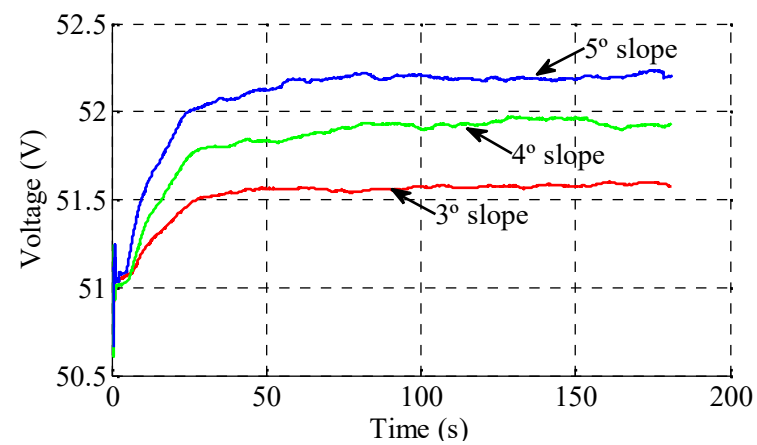

Fig. 16. Batteries voltages of experimental study of regenerative braking

Result of the regenerative braking experimental study is given in Table III. The torque controlled DC motor has $63.5 \%$ efficiency at $300 \mathrm{rpm}$. Energy conversion from the DC motor to batteries is given in Fig. 17.

TABLE III. RESULTS OF THE EXPERIMENTAL STUDY OF REGENERATIVE BRAKING.

\begin{tabular}{|c|c|c|c|}
\hline 300 Rpm Reference & $\mathbf{3}^{\mathbf{0}}$ Slope & $\mathbf{4}^{\mathbf{0}}$ Slope & $\mathbf{5}^{\mathbf{0}}$ Slope \\
\hline Load & $10.2 \mathrm{Nm}$ & $13.6 \mathrm{Nm}$ & $17 \mathrm{Nm}$ \\
\hline DC Motor Current & $1.8 \mathrm{~A}$ & $2.4 \mathrm{~A}$ & $3 \mathrm{~A}$ \\
\hline Current of Batteries & $4 \mathrm{~A}$ & $6.1 \mathrm{~A}$ & $7.66 \mathrm{~A}$ \\
\hline Voltage of Batteries & $51.55 \mathrm{~V}$ & $51.9 \mathrm{~V}$ & $52.2 \mathrm{~V}$ \\
\hline Regen. Power & $206.2 \mathrm{~W}$ & $316.59 \mathrm{~W}$ & $399.85 \mathrm{~W}$ \\
\hline Regen. Efficiency & $64.42 \%$ & $74.91 \%$ & $74.96 \%$ \\
\hline
\end{tabular}

\begin{tabular}{|c|c|}
\hline $280 \mathrm{VDC}$ \\
$1.8 \mathrm{~A} / 2.4 \mathrm{~A} / 3 \mathrm{~A}$ \\
$504 \mathrm{~W} / 672 \mathrm{~W} / 840 \mathrm{~W}$ \\
Input Power
\end{tabular}$\rightarrow \begin{gathered}\text { DC Motor } \\
\% 663.5 \\
\text { Efficiency }\end{gathered} \rightarrow \begin{gathered}320 \mathrm{~W} / 427 \mathrm{~W} / 534 \mathrm{~W} \\
\text { Output Power }\end{gathered}$

$\rightarrow \begin{gathered}\text { In-Wheel Motor } \\
64.4 \% / 74.9 \% / 74.7 \\
\text { Regenerative } \\
\text { Efficiency }\end{gathered} \rightarrow \longrightarrow$\begin{tabular}{c|}
$206 \mathrm{~W} / 317 \mathrm{~W} / 400 \mathrm{~W}$ \\
Regenerative \\
Braking Power
\end{tabular}

Fig. 17. Energy conversion from the DC motor to the batteries.

Speed control during regenerative braking with PID 
controller is carried both in the simulation study and the experimental study. The simulation results validate the experimental results as revolution speeds, battery current and battery voltage. Also PID controller parameters are common in the simulation study and the experimental study. Current graphs of the simulation study and the experimental study have very close results. Voltage graphs are different because of the simulation time. Results of experimental study numbers also consistent and mathematical proved.

The graphics show if a light weight four wheel drive electric vehicle goes down top of the hill with $3^{\circ}, 4^{\circ}$ and $5^{\circ}$ slopes, the IWM has enough torque to control the speed of the vehicle that four wheel drive, $300 \mathrm{~kg}$ weight.

\section{CONCLUSIONS}

In this study, speed is controlled during regenerative breaking on 3 different slopes. The test conditions for the both the simulation study and the experimental study are $3^{\circ}$, $4^{\circ}$ and $5^{\circ}$ slopes and a lightweight electric vehicle with four wheel drive, $300 \mathrm{~kg}$ weight. The speed of the regenerative braking is controlled at $300 \mathrm{rpm}$ and the batteries are charged during regenerative breaking. In the future studies, the regenerative breaking experiment can be done with different controller using different speed reference values.

There are numerous studies for regenerative braking application in literature. Cooperation braking, anti-lock braking, maximum energy recovery, control and management strategy, stability control are studied as regenerative braking. This study is different from the studies in literature as speed control of regenerative braking on downhill with different slope degrees.

\section{REFERENCES}

[1] W.-P. Chiang, D. Yin, H. Shimizu, "Slip-based regenerative ABS control for in-wheel-motor drive EV", J. Chinese Inst. Eng., vol. 38 , no. 2, pp. 220-231, 2015. [Online]. Available: https://doi.org/ 10.1080/02533839.2014.955974

[2] L. Li, X. Li, X. Wang, Y. Liu, J. Song, X. Ran, “Transient switching control strategy from regenerative braking to anti-lock braking with a semi-brake-by-wire system", Veh. Syst. Dyn., vol. 54, no. 2, pp. 231257, 2016. [Online]. Available: https://doi.org/ $10.1080 / 00423114.2015 .1129059$

[3] P. Fajri, Sangin Lee, V. A. K. Prabhala, M. Ferdowsi, "Modeling and integration of electric vehicle regenerative and friction braking for motor/dynamometer test bench emulation", IEEE Trans. Veh. Technol., vol. 65, no. 6, pp. 4264-4273, 2016. [Online]. Available: https://doi.org/10.1109/TVT.2015.2504363

[4] J. Ko, S. Ko, H. Son, B. Yoo, J. Cheon, H. Kim, "Development of brake system and regenerative braking co-operative control algorithm for automatic transmission-based hybrid electric vehicle", IEEE Trans. Veh. Technol., vol. 64, no. 2, pp. 431-440, 2014. [Online]. Available: https://doi.org/10.1109/TVT.2014.2325056

[5] B. Wang, X. Huang, J. Wang, X. Guo, X. Zhu, "A robust wheel slip ratio control design combining hydraulic and regenerative braking systems for in-wheel-motors-driven electric vehicles", J. Franklin Inst., vol. 352, no. 2, pp. 577-602, 2015. [Online]. Available: https://doi.org/10.1016/j.jfranklin.2014.06.004

[6] M. H. Kwon, J. H. Park, G. S. Gwak, J. W. Huh, H. K. Choi, H. Hwang, "Cooperative control for friction and regenerative braking systems considering dynamic characteristic and temperature condition", International Journal of Automotive Technology, vol. 17, no. 3, pp. 437-446, 2016. [Online]. Available: https://doi.org/10.1007/s12239-016-0045-6

[7] L. Li, X. Li, X. Wang, J. Song, K. He, C. Li, “Analysis of downshift's improvement to energy efficiency of an electric vehicle during regenerative braking", Applied Energy, vol. 176, pp. 125-137, 2016 [Online]. Available: https://doi.org/10.1016/j.apenergy.2016.05.042

[8] R. Maia, M. Silva, R. Araujo, U. Nunes, "Electrical vehicle modeling: A fuzzy logic model for regenerative braking", Expert Syst. Appl., vol. 42, no. 22, pp. 8504-8519, 2015. [Online]. Available: https://doi.org/10.1016/j.eswa.2015.07.006

[9] X. Nian, F. Peng, H. Zhang, "Regenerative braking system of electric vehicle driven by brushless DC motor", IEEE Trans. Ind. Electron., vol. 61, no. 10, pp. 5798-5808, 2014. [Online]. Available: https://doi.org/10.1109/TIE.2014.2300059

[10] A. Uysal, R. Bayir, "Design and implementation of switched reluctance motor driver for industrial controller", in Fourth Int. Conf. IEEE Power Engineering, Energy and Electrical Drives (POWERENG 2013), Istanbul, Turkey, 2013, pp. 770-774. [Online] Available: https://doi.org/10.1109/PowerEng.2013.6635707

[11] J. Huang, D. Qin, Z. Peng, "Effect of energy-regenerative braking on electric vehicle battery thermal management and control method based on simulation investigation", Energy Convers. Manag., vol. 105, pp. 1157-1165, 2015. [Online]. Available: https://doi.org/10.1016/j.enconman.2015.08.080

[12] L. Li, Y. Zhang, C. Yang, B. Yan, C. Marina Martinez, "Model predictive control-based efficient energy recovery control strategy for regenerative braking system of hybrid electric bus", Energy Convers. Manag., vol. 111, pp. 299-314, 2016. [Online]. Available: https://doi.org/10.1016/j.enconman.2015.12.077

[13] B. Long, S. Lim, Z. Bai, J. Ryu, K. Chong, "Energy management and control of electric vehicles, using hybrid power source in regenerative braking operation", Energies, vol. 7, no. 7, pp. 4300-4315, 2014 bus", Energy Convers. Manag., vol. 111, pp. 299-314, 2016 [Online]. Available: https://doi.org/10.3390/en7074300

[14] S. A. Oleksowicz, K. J. Burnham, A. Southgate, C. McCoy, G. Waite, G. Hardwick, C. Harrington, R. McMurran, "Regenerative braking strategies, vehicle safety and stability control systems: critical usecase proposals", Veh. Syst. Dyn., vol. 51, pp. 684-699, 2013 [Online]. Available: https://doi.org/10.1080/00423114.2013.767462

[15] G. Xu, K. Xu, C. Zheng, X. Zhang, T. Zahid, "Fully electrified regenerative braking control for deep energy recovery and maintaining safety of electric vehicles", IEEE Trans. Veh. Technol., vol. 65 , no. 3, pp. 1186-1198, 2016. [Online]. Available: https://doi.org/10.1109/TVT.2015.2410694

[16] G. Xu, W. Li, K. Xu, Z. Song, "An intelligent regenerative braking strategy for electric vehicles", Energies, vol. 4, no. 9, pp. 1461-1477, 2011. [Online]. Available: https://doi.org/10.3390/en4091461

[17] Y. Luo, Y. Han, L. Chen, K. Li, "Downhill safety assistance control for hybrid electric vehicles based on the downhill driver's intention model", in Proc. IMechE. Part D: J. of Automobile Engineering, vol. 229, no. 13, pp. 1848-1860, 2015. [Online]. Available: https://doi.org/10.1177/0954407014567908

[18] L. Zhai, T. Sun, J. Wang, "Electronic stability control based on motor driving and braking torque distribution for a four in-wheel motor drive electric vehicle", IEEE Trans. Veh. Technol., vol. 65, no. 6 , pp. 4726-4739, 2016. [Online]. Available: https://doi.org/10.1109/ TVT.2016.2526663

[19] L. Zhai, T. M. Sun, Q. N. Wang, J. Wang, "Lateral stability control of dynamic steering for dual motor drive high speed tracked vehicle", International Journal of Automotive Technology, vol. 17, no. 6, pp. 1079-1090, 2016. [Online]. Available: https://doi.org/ 10.1007/s12239-016-0105-y

[20] T. C. Huang, M. A. El-Sharkawi, D. Archana, K. Kalyani, B. S. Prasad, "Efficiency optimization control of induction motor using Fuzzy logic", Int. Journal of Soft Computing and Engineering, vol. 2, no. 3, pp. 327-332, 2012.

[21] M. Sreejeth, M. Singh, P. Kumar, "Particle swarm optimisation in efficiency improvement of vector controlled surface mounted permanent magnet synchronous motor drive", IET Power Electronics, vol. 8 , no. 5 , pp. $760-769,2015$. [Online]. Available: https://doi.org/ 10.1049/iet-pel.2014.0399

[22] A. Uysal, R. Bayir, "Real-time condition monitoring and fault diagnosis in switched reluctance motors with Kohonen neural network", J. Zhejiang Univ. Sci. C, vol. 14, no. 12, pp. 941-952, 2013. [Online]. Available: https://doi.org/10.1631/jzus.C1300085

[23] E. Soylu, R. Bayir, "Measurement of electrical conditions of rechargeable batteries", Meas. Control, vol. 49, no. 2, pp. 72-81, 2016. [Online]. Available: https://doi.org/10.1177/002029401662 9178 